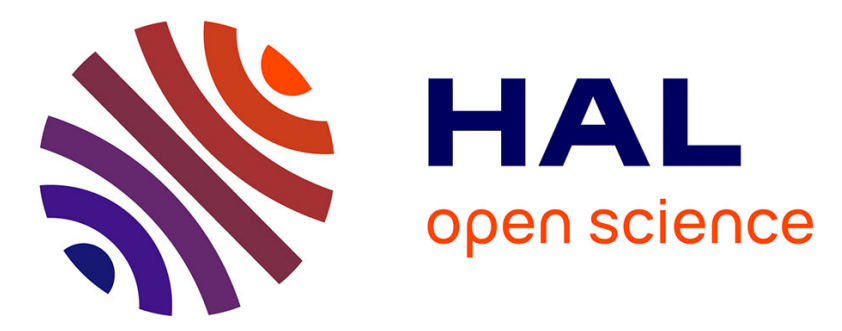

\title{
Segmental mobility and glass transition of poly(ethylene-vinyl acetate) copolymers: Is there a continuum in the dynamic glass transitions from PVAc to PE?
}

\author{
J.A.S Puente, B Rijal, Laurent Delbreilh, K Fatyeyeva, Allisson Saiter, E \\ Dargent
}

\section{To cite this version:}

J.A.S Puente, B Rijal, Laurent Delbreilh, K Fatyeyeva, Allisson Saiter, et al.. Segmental mobility and glass transition of poly(ethylene-vinyl acetate) copolymers: Is there a continuum in the dynamic glass transitions from PVAc to PE?. Polymer, 2015, 76, pp.213-219. 10.1016/j.polymer.2015.09.007 . hal-01199668

\section{HAL Id: hal-01199668 \\ https://hal.science/hal-01199668}

Submitted on 15 Sep 2015

HAL is a multi-disciplinary open access archive for the deposit and dissemination of scientific research documents, whether they are published or not. The documents may come from teaching and research institutions in France or abroad, or from public or private research centers.
L'archive ouverte pluridisciplinaire HAL, est destinée au dépôt et à la diffusion de documents scientifiques de niveau recherche, publiés ou non, émanant des établissements d'enseignement et de recherche français ou étrangers, des laboratoires publics ou privés. 


\title{
Segmental mobility and glass transition of poly(ethylene-vinyl acetate) copolymers : Is there a continuum in the dynamic glass transitions from PVAc to PE?
}

\author{
J. A. S. Puente ${ }^{1,2,3,4}$, B. Rijal ${ }^{1,2}$, L. Delbreilh ${ }^{1,2}$, K. Fatyeyeva ${ }^{1,3,4}$, A. Saiter ${ }^{1,2}$, E. Dargent ${ }^{1,2} *$
}

\begin{abstract}
The segmental dynamics of amorphous poly(ethylene-vinyl acetate) copolymers (from PVAc to EVA50) were studied. In that sample set with similar backbone stiffness and different amount of dipoles, the dynamic glass transition was investigated by Modulated Temperature Differential Scanning Calorimetry and Broadband Dielectric Spectroscopy measurements. A decrease of the cooperativity length scale was obtained with the vinyl acetate (VAc) content decreasing. On the other hand, there was no modification of the temperature dependence of the relaxation time. Thus, the fragility value is quite constant whatever the VAc content. These results show that fragility and cooperativity have two different origins. An extrapolation to nonconstrained polyethylene amorphous phase was proposed and new glass transition temperature and fragility values were determined.
\end{abstract}

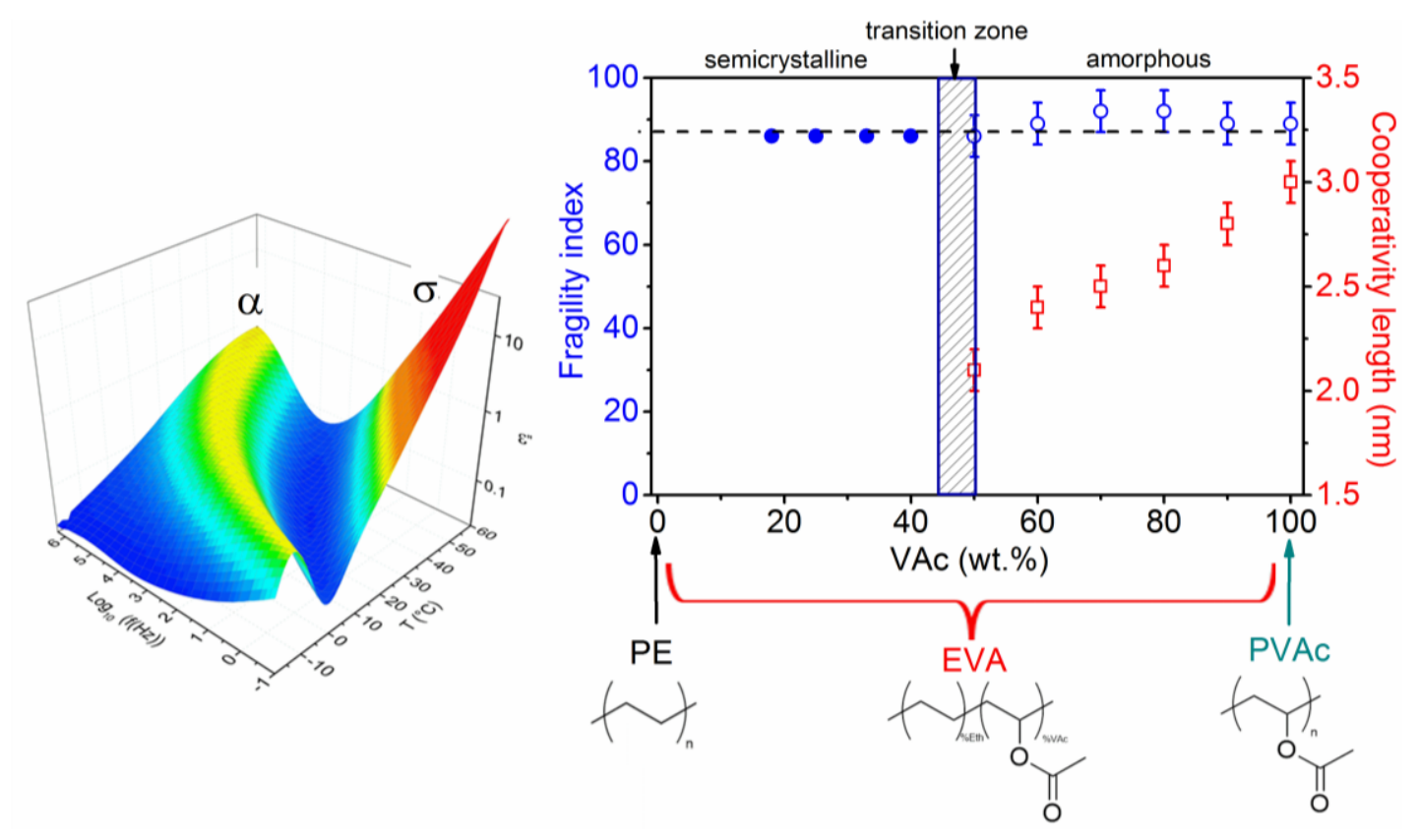

Highlights

1. Amorphous phase mobility is studied for poly(ethylene-vinyl acetate) copolymers

2. Fragility is constant from PVAc to EVA50 while cooperativity length decreases

3. New extrapolated $T_{g}$ and fragility values are proposed for PE

4. Fragility and cooperativity are not governed by the same macromolecular properties

Keywords

Amorphous phase, dynamic glass transition, poly(ethylene-vinyl acetate)

\footnotetext{
$1^{1}$ Normandie Univ

2 AMME-LECAP EA 4528 International Laboratory, Université et INSA de Rouen, Av. de l'Université BP 12, 76801 Saint Etienne du Rouvray Cedex, France

3 Laboratoire Polymères, Biopolymères et Surfaces, Bd. Maurice de Broglie, 76821 Mont Saint Aignan Cedex, France

4 UMR 6270 CNRS \& FR 3038, Bd. Maurice de Broglie, 76821 Mont Saint Aignan Cedex, France ${ }^{1}$

* Corresponding author: eric.dargent @ univ-rouen.fr
}

Access online : http://dx.doi.org/10.1016/j.polymer.2015.09.007 


\section{$\underline{\text { Introduction }}$}

The relaxation processes of the polymers associated with their glass transition, also called $\alpha$ relaxation processes, have been widely studied but the links between macromolecular chain chemistry, microstructure and $\alpha$ relaxation dynamics are not yet fully understood [1-3]. The main experimental common feature of all the glass-formers is the viscous slowing down of the structural relaxation dynamic, observed in a supercooled liquid close to the glass transition temperature $\left(T_{g}\right)$. On this basis, several authors proposed models and approaches to classify this temperature dependence of the dynamic viscosity and/or relaxation times [1-7]. Angell has proposed a classification of glass-forming liquids by analyzing the viscosity variations as a function of $T_{g}$-normalized plot, so called "fragility curve" [4]. Therefore, structural relaxation temperature dependences can be defined as Super-Arrhenius, due to a possible behavior between two extreme limits: "strong" glass forming liquids for which the viscosity variations (or relaxation time) are very slow and follow an Arrhenius law, and the "fragile" glass forming liquids for which a very abrupt and steep non-Arrhenian variations can be observed. The fragility index $(m)$ quantifies the steepness of the temperature dependence of the relaxation time $(\tau)$ close to $T_{g}$ (defined at $\tau=100 \mathrm{~s}$ ) and can be calculated as follows:

$$
m=\left.\frac{d \log (\tau)}{d\left(T / T_{g}\right)}\right|_{T=T_{g}}
$$

The fragility values for different materials such as polymers, metallic glasses, organic and inorganic ionic glasses, and for small organic molecules were summarized [5]. A completely strong behavior is characterized by $m=16$, while a highly fragile material exhibits $m$ value close to 150-200. For polymers, values go usually from $\sim 50$ to $~ 160$ [6,7]. As an example, a "fragile" behavior was reported for polymers with rigid backbone such as polycarbonate $(\mathrm{PC})(m \sim 132)$ [8,9] and polyethylene terephthalate (PET) $(m \sim 156)$ [10]. In the case of polymers with flexible backbone and steric effects related to a pendant group, fragility indexes are lower: $m \sim 103-145$ for polymethylmethacrylate (PMMA) [3,8], $m \sim 110$ for polyhydroxyalcanoates (PHAs) [11], and $m \sim 115-140$ for unsaturated polyester resins [12]. Moreover, for polymers possessing a more complex structure, the temperature dependence of viscosity is strong (fragile behavior) [6,13]. For polymers possessing a highly flexible backbone without side groups, the relaxation behavior becomes stronger: polydimethylsiloxane (PDMS) $(m \sim 80-100)$ [6], polyisoprene (PIP) $(m \sim 55-77)[\mathbf{1 , 1 4}]$ polyvinyl acetate (PVAc) $(m \sim 95)$ [5] and polyethylene (PE) $(m \sim 46)$ [15]. Polymers with non-polar and flexible chain structures and without important steric effects related to pendant groups show weak temperature dependence of viscosity (strong behavior). Thus, such approach has revealed that the polymer chemical structure affects its relaxation behavior [6].

Several approaches have been proposed to explain the correlation between the fragility and the molecular mobility near $T_{g}[\mathbf{1 0 , 1 6 , 1 7 ]}$. According to the theory proposed by Adam and Gibbs [18], it is well accepted that the $\alpha$ relaxation process is cooperative in nature: a structural unit can move only if a certain number of neighboring structural units move also. Besides, the molecular motions are mainly governed by the intermolecular interactions having important effects in the viscous slowing down of molecular dynamics when the glass-forming liquid is cooled-down close to $T_{g}$. Thus, the notion of Cooperative Rearranging Region (CRR) was introduced, and the CRR size can be estimated according to different models and theories in terms of characteristic length scale or in terms of structural unit number [16,19-22]. According to Donth [22], a CRR can be estimated by the von Laue approach describing a system with a fluctuating temperature. Each CRR represents a fluctuating region of molecular mobility (relaxation time) and it can be represented as a group of "sub-subsystems" called structural units, each one having its own glass transition temperature related to its own relaxation time. The CRR size evolution has been experimentally studied to understand how the cooperativity correlates with other relaxation parameters such as fragility, glass transition temperature, relaxation time or molecular weight [12,23-25]. Recently, the fragility/cooperativity relation has been studied in complex systems of semicrystalline polymer blends (polyvinylidene fluoride (PVDF)/PMMA) containing multiwall carbon nanotubes [26]. However, the study of the influence of the dipole amount on CRR by using the same chemical structure has not deeply investigated.

As explained previously, several works correlate the fragility with the chemical backbone stiffness. Thus, the aim of this work is to correlate the relaxation time behavior close to $T_{g}$ with the cooperative motions during the $\alpha$ relaxation, by decreasing the dipolar interchain interactions in materials with a similar backbone flexibility and without microstructure effect (fully amorphous polymers). PVAc and its random ethylene copolymers, so-called poly(ethylene-co-vinyl acetate) (EVA) are good candidates as shown in Fig. 1. As explained by Kummali et al [27], EVA are random copolymers composed of VAc polar units and ethylene apolar units. The interchain dipolar interactions are expected to decrease as a consequence of the VAc content decreasing. It is known that EVA could be wholly amorphous or semicrystalline depending on the ethylene content. Wholly amorphous EVA polymers are obtained when VAc content is higher than 40 or 50 wt.\% [12,27,28]. For semicrystalline EVA, a part of the amorphous phase becomes constrained by the polyethylene crystalline regions (constrained amorphous phase) [27]. It is well-known that the presence of a crystalline phase can modify the cooperativity characteristics $[\mathbf{2 9}, 30]$ and the fragility [11] of polymers. However, few works have reported fragility/cooperativity studies on wholly amorphous systems, i.e. without confinement effects related to crystals that can modify the mobility of the nonconstrained amorphous phase, and by keeping the same polymer backbone and dipolar pending group [31,32]. Thus, the aim of this work is to study the influence of the dipolar interactions (VAc content) on the fragility and cooperativity values for a set of samples with similar polymer backbone stiffness.

\section{Materials}


PVAc pellets with a weight-average molecular weight $\left(M_{w}\right)$ close to $500 \mathrm{~kg} / \mathrm{mol}$ were provided by Aldrich Chemical Co. EVA copolymers were supplied from two companies. LEVAPREN ${ }^{\circledR}$ 700, 800 and 900 containing 70, 80 and 90 wt. $\%$ of VAc groups, respectively, and $M_{w}=$ $270 \mathrm{~kg} / \mathrm{mol}$ were kindly provided by Lanxess Co. LEVAPREN $^{\circledR} 500$ and 600 with 50 and 60 wt. \% of VAc groups, respectively, and $M_{w}=250 \mathrm{~kg} / \mathrm{mol}$ were obtained from Bayer Co. Samples are called EVAxx where xx is the VAc wt \%. Dichloromethane (99\%, Alfa Aesar) was used as received.

A solution containing $10 \mathrm{wt} \%$ of polymer in dichloromethane was prepared by mechanical stirring at room temperature $\left(20 \pm 2{ }^{\circ} \mathrm{C}\right)$. Then, this solution was cast on a glass plate and dried during $16 \mathrm{~h}$ at room temperature. The residual solvent was eliminated in an oven during $7 \mathrm{~h}$ at $80^{\circ} \mathrm{C}$. Films were stored in a desiccator over $\mathrm{P}_{2} \mathrm{O}_{5}$ (Acros) to avoid sorption of moisture. The average thickness of polymer films was $\sim 130 \mu \mathrm{m}$.

a)<smiles>CC(=O)OC(CC(C)(C)C)C(C)C</smiles>

Figure 1. Chemical structure of: a) PVAc and b) EVA copolymers.

\section{Characterization techniques}

Modulated Temperature Differential Scanning Calorimetry (MT-DSC) experiments were performed on a Thermal Analysis instrument (TA DSC Q100). To prevent the oxidative degradation, a nitrogen atmosphere was used for all the measurements $(50 \mathrm{~mL} / \mathrm{min})$. The temperature calibration was performed with benzophenone and indium standards and energy calibration with indium standard. The specific heat capacity was measured by applying the calibration carried out with a sapphire as a reference. The sample of about $5 \mathrm{mg}$ was encapsulated in aluminum pan. The optimal conditions to perform specific heat capacity measurements can be obtained by using different modes $[33,34]$. In our case the measurements were performed by using the heat-cool modulation parameters (oscillation amplitude $A= \pm 1 \mathrm{~K}$, cooling rate $q=0.5 \mathrm{~K} / \mathrm{min}$ and oscillation period $p=60 \mathrm{~s}$ ), the temperature range scanned being adapted to the glass transition temperature of each material. The complex heat capacity modulus $\left|\mathrm{C}_{\mathrm{p}}^{*}\right|$ is defined from MT-DSC measurements as follows:

$\left|C_{p}^{*}\right|=\frac{A_{q}}{A_{\beta}} \cdot \frac{1}{m_{\text {sample }}}$

where $A_{q}$ is the amplitude of the modulated heat flow, $A_{\beta}$ is the amplitude of the modulated heating rate and $m_{\text {sample }}$ is the sample mass. A phase lag $(\varphi)$ exists between the calorimeter response (total heat flow) and the heating modulation during the temperature modulation [35]. The two apparent heat capacity components, $C$ ' (in-phase component) and $C$ "' (outof-phase component), can be obtained by the deconvolution procedure proposed by Lacey et al. [36] (Eq. 3 and 4):

$$
\begin{aligned}
& C^{\prime}=\left|C_{p}^{*}\right| \cdot \cos \varphi \\
& C^{\prime \prime}=\left|C_{p}^{*}\right| \cdot \sin \varphi
\end{aligned}
$$

Broadband dielectric spectroscopy (BDS) measurements were carried out with an Alpha Analyzer from Novocontrol (frequency range: $10^{-1} \mathrm{~Hz}-10^{6} \mathrm{~Hz}$ ). A circle film with a diameter of $30 \mathrm{~mm}$ of the studied material was placed between parallel gold electrodes. The temperature was controlled with a Quatro Cryosystem through a heated flow of nitrogen gas from $-130^{\circ} \mathrm{C}$ to $80^{\circ} \mathrm{C}$ and the protocol was defined by using WinDeta ${ }^{\odot}$ (version 5.8) from Novocontrol Technologies. The dielectric relaxation curves were analyzed with the Havriliak-Negami (HN) complex function [37] by using WinFit ${ }^{\odot}$ software (version 3.3) and the Eq. 5:

$$
\varepsilon^{*}(\omega)=\varepsilon_{\infty}+\frac{\Delta \varepsilon_{H N}}{\left[1+\left(i \omega \tau_{H N}\right)^{\alpha_{H N}}\right]^{\beta_{H N}}}
$$

where $\varepsilon^{*}$ is the complex permittivity, $\omega$ is the angular pulsation ( $\omega=2 \pi f$ where $f$ is the frequency), $\varepsilon_{\infty}$ is the permittivity value when $\omega \rightarrow \infty, \Delta \varepsilon_{H N}$ is the dielectric strength, $\tau_{H N}$ is the relaxation time and $\alpha_{H N}$ and $\beta_{H N}$ are the symmetric and the asymmetric broadening factors, respectively.

\section{Results and discussion}

\section{Thermal analysis}

From MT-DSC measurements, the $C$ ' signal as a function of temperature at the glass transition appears usually as an endothermic step and the $C$ " signal reveals a peak with a maximum at the dynamic glass transition temperature $T_{\alpha}$. Figure 2 shows the temperature shift of the C' step and C" peak to lower temperatures when the ethylene content increases. $\mathrm{T}_{\alpha}$ values are reported in Table 1 . 


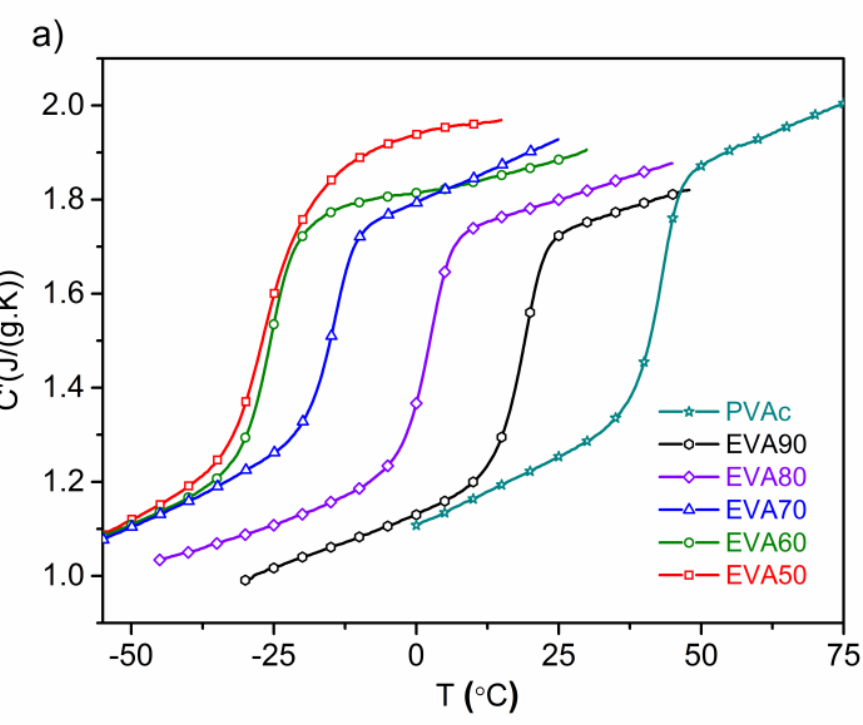

b)

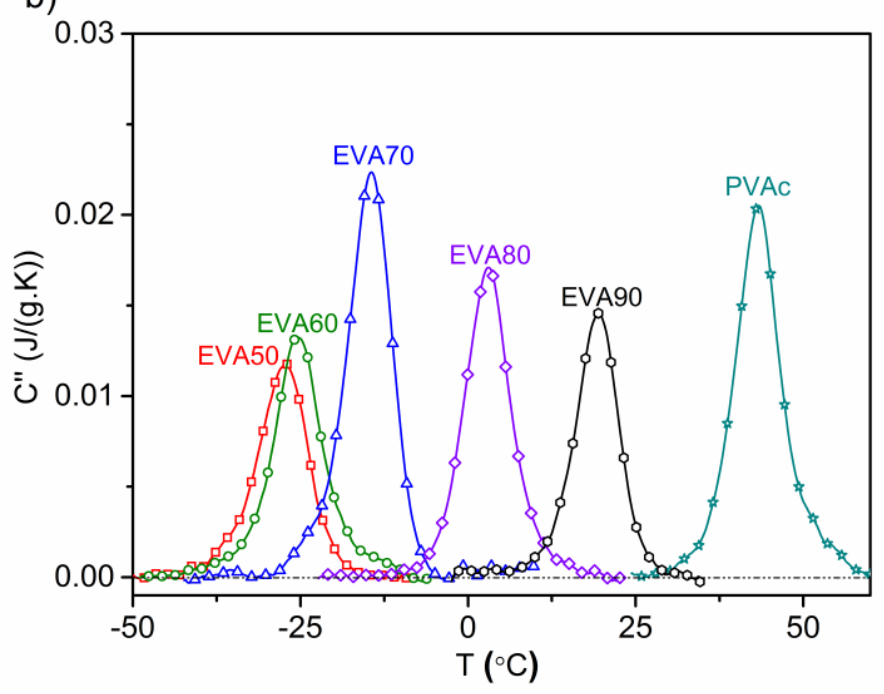

components of the complex heat capacity for PVAc and EVA copolymers.

The molecular mobility of EVA and PVAc is investigated with MT-DSC using the CRR concept. According to Donth's approach mentioned in the introduction, the CRR average volume $\left(V_{\alpha}=\xi_{\alpha}{ }^{3}\right)$ and the characteristic length of cooperativity at the glass transition $\xi_{\alpha}$ can be estimated according to the following equation [22]:

$\xi_{\alpha}=\left(\frac{\Delta\left(1 / C_{p}\right)}{\rho(\delta T)^{2}} k_{B} T_{\alpha}^{2}\right)^{1 / 3}$

where $\Delta\left(1 / C_{p}\right)=1 / C_{\text {pglass }}-1 / C_{\text {pliquid }}$ taken at $\mathrm{T}_{\alpha}[\mathbf{2 2}], \rho$ is the density of the glass-former, $k_{B}$ the Boltzmann constant, $T_{\alpha}$ is the characteristic peak temperature, and $\delta T$ is the average temperature fluctuation related to the dynamic glass transition of an average CRR. The number of structural units per CRR noted $N_{\alpha}$ can be estimated by:

$N_{\alpha}=\frac{\rho N_{A} V_{\alpha}}{M_{0}}=\frac{N_{A} \Delta\left(1 / C_{p}\right)}{M_{0}(\delta T)^{2}} k_{B} T_{\alpha}^{2}$

where $N_{A}$ is the Avogadro number and $M_{0}$ is the molar mass of the relevant structural unit. In the case of PVAc, $M_{0}$ is equal to the molar mass of the VAc group $\left(M_{V A c}=86\right.$ $\mathrm{g} / \mathrm{mol})$. The $M_{0}$ values for each EVA copolymer were calculated by using the molar mass and the molar content $(x)$ of the VAc group and the molar mass of the ethylene group $\left(M_{E t h}=28 \mathrm{~g} / \mathrm{mol}\right)$ as follows: $M_{0 \text { EVAxx }}=M_{V A c}(x)+M_{E t h}(1-$ $x$ ). As an example, EVA50 contains $23 \mathrm{~mol} \%$ of VAc groups $(x=0.23)$, then $M_{O E V A 50}=42.2 \mathrm{~g} / \mathrm{mol}$.

Figure 2. a) In-phase $\left(C^{\prime}\right)$ and b) out-of-phase $\left(C^{\prime \prime}\right)$

Table 1: MT-DSC results: the temperature of the maximum of the $C$ ' ' peak $\left(T_{\alpha}\right)$, the heat capacity step at $T_{\alpha}\left(\Delta C_{p T \alpha}\right)$, the density $(\rho)$, the mean temperature fluctuation $(\delta T)$; the molecular weight of the relaxation unit $\left(M_{0}\right)$ and the Donth's model values: the cooperativity length $\left(\xi_{\alpha}\right)$ and the number of equivalent relaxation units in a CRR $\left(N_{\alpha}\right)$ for PVAc and EVA copolymers.

\begin{tabular}{|c|c|c|c|c|c|c|c|c|}
\hline Sample & $\begin{array}{c}\mathbf{T}_{\alpha} \\
\left({ }^{\circ} \mathbf{C}\right)\end{array}$ & $\begin{array}{c}\Delta C \mathbf{p}_{\mathrm{T} \alpha} \\
\left(\mathrm{J} /\left(\mathrm{g}^{\circ} \mathrm{C}\right)\right)\end{array}$ & $\begin{array}{c}\mathbf{T}_{\alpha} \\
\left({ }^{\circ} \mathbf{C}\right)\end{array}$ & $\begin{array}{c}\rho \\
\left(\mathrm{g} / \mathrm{cm}^{3}\right)\end{array}$ & $\delta \mathbf{T}\left({ }^{\circ} \mathbf{C}\right)$ & $\begin{array}{c}\mathrm{M}_{0} \\
(\mathrm{~g} / \mathrm{mol})\end{array}$ & $\xi_{\alpha}(\mathbf{n m})$ & $\mathbf{N}_{\alpha}$ \\
\hline PVAc & 41.5 & 0.51 & 41.5 & 1.19 & 3.1 & 86.0 & 3.0 & 225 \\
\hline EVA90 & 19.0 & 0.50 & 19.0 & 1.15 & 3.3 & 71.2 & 2.8 & 221 \\
\hline EVA80 & 3.0 & 0.49 & 3.0 & 1.11 & 3.5 & 60.8 & 2.6 & 194 \\
\hline EVA70 & -14.5 & 0.45 & -14.5 & 1.07 & 3.7 & 53.1 & 2.5 & 183 \\
\hline EVA60 & -25.5 & 0.53 & -25.5 & 1.04 & 3.8 & 47.0 & 2.4 & 181 \\
\hline EVA50 & -27.5 & 0.62 & -27.5 & 1.00 & 3.8 & 42.2 & 2.1 & 130 \\
\hline
\end{tabular}

The impact of the different parameters on the $\xi_{\alpha}$ values (Eq. 6) was verified. The density value varies with the VAc content, from $1.00 \mathrm{~g} / \mathrm{cm}^{3}$ for EVA50 up to 1.19 $\mathrm{g} / \mathrm{cm}^{3}$ for PVAc (Table 1). It has been noted that the 
influence on the $\xi_{\alpha}$ values is not significant even without the effect of the density variations (Fig. 3). On the other hand, the mean fluctuation temperature $(\delta T)$ at the glass transition has an important effect on the cooperativity (Eq. 6). The Gaussian peak in $C$ " becomes wider when the VAc content decreases, from $3.1{ }^{\circ} \mathrm{C}$ for PVAc up to $3.8^{\circ} \mathrm{C}$ for EVA50 (Table 1). Such behavior can be explained by a broader relaxation time distribution, i.e. an increasing heterogeneity of the molecular dynamics related in the glass transition process due to spatial composition heterogeneities $[22,25,29]$.

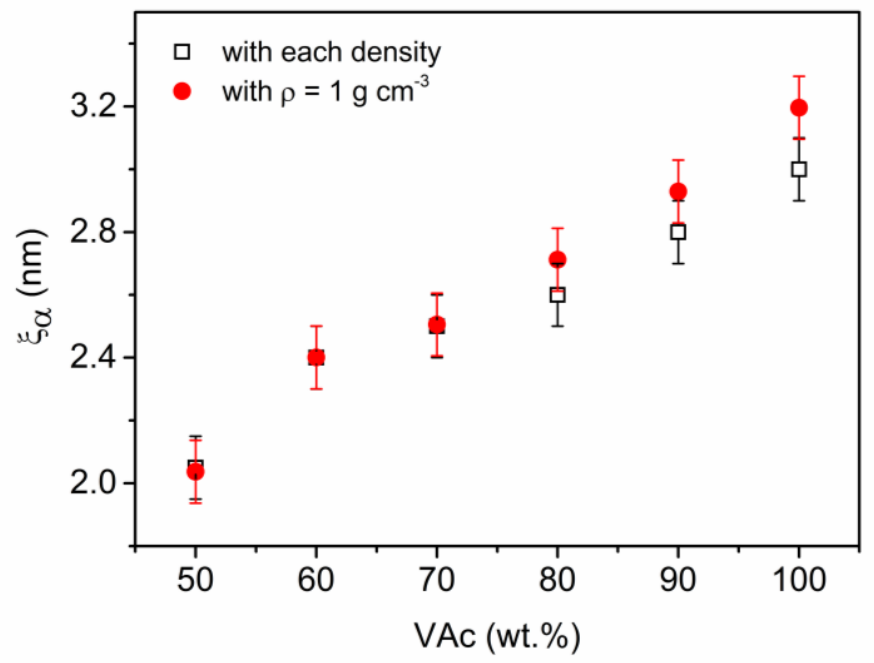

Figure 3. Cooperativity length $\left(\xi_{\alpha}\right)$ evolution with the VAc content.
DSC measurements is in good agreement with the literature (2.9 $\pm 2 \mathrm{~nm} \mathrm{[39])} \mathrm{and} \mathrm{could} \mathrm{be} \mathrm{compared} \mathrm{with} \mathrm{the}$ cooperativity lengths in the amorphous EVA copolymers (VAc content $>40$ wt. $\%$ ). Therefore, a decrease of $\xi_{\alpha}$ values (Table 1) was related to the decrease of the dipole amount in the chain structure, i.e. to lower intermolecular interactions.

\section{Dielectric analysis}

The main relaxation processes were studied by means of BDS measurements. The temperature dependence of the relaxation time allows investigating the nature of the cooperative motions of the structural relaxation.

The $\alpha$ relaxation behavior of PVAc has been reported in several studies and for different geometries, such as the bulk [38,41-43], with a confinement effect in nanolayers [44], or a deposited layer onto a silica surface [45]. Regarding the $\alpha$ relaxation of EVA copolymers, the semicrystalline materials were mainly studied $[27,46-48]$.

In Fig. 4, a 3-D plot of the imaginary part of the permittivity, or dielectric loss $(\varepsilon$ "), shows the variations of the $\alpha$ relaxation as a function of frequency $(f)$ and temperature $(T)$ for the EVA70, as an example. The $\alpha$ relaxation in the $\varepsilon$ " signal is observed as a dissipation peak associated to the structural relaxation. Moreover, ionic conductivity $(\sigma)$ phenomenon appears at temperatures higher than $T_{g}$ and lower frequencies. In the case of the $\varepsilon^{\prime}$ signal, the $\alpha$ relaxation is detected as a permittivity step (not shown here).

The cooperativity processes for PVAc have been widely studied [38-40]. The $\xi_{\alpha}$ value obtained from MT-

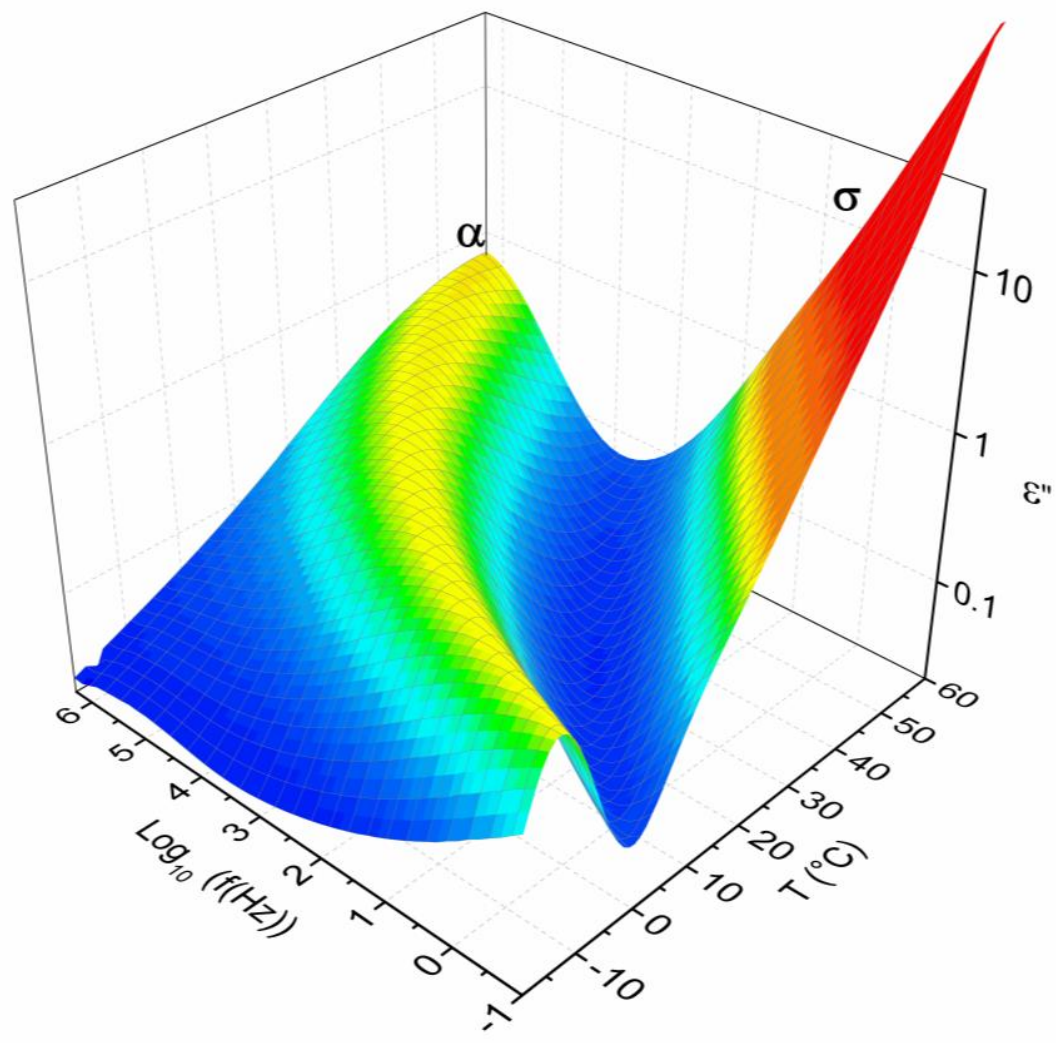

Figure 4. 3-D plot from BDS analysis for EVA70: dielectric loss ( $\varepsilon$ ") versus frequency $(f)$ and temperature $(T)$. 
The isothermal BDS curves can be normalized to obtain master curves where the maximum of the $\alpha$ relaxation is at $\varepsilon " / \varepsilon "{ }_{\text {max }}=1$ and $f / f_{\text {max }}=1$.

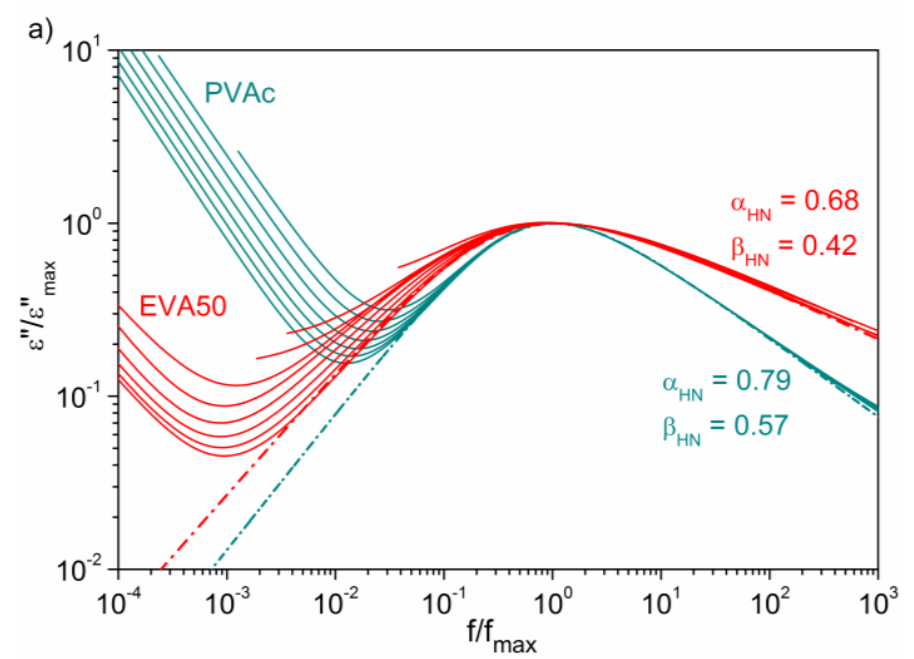

b)

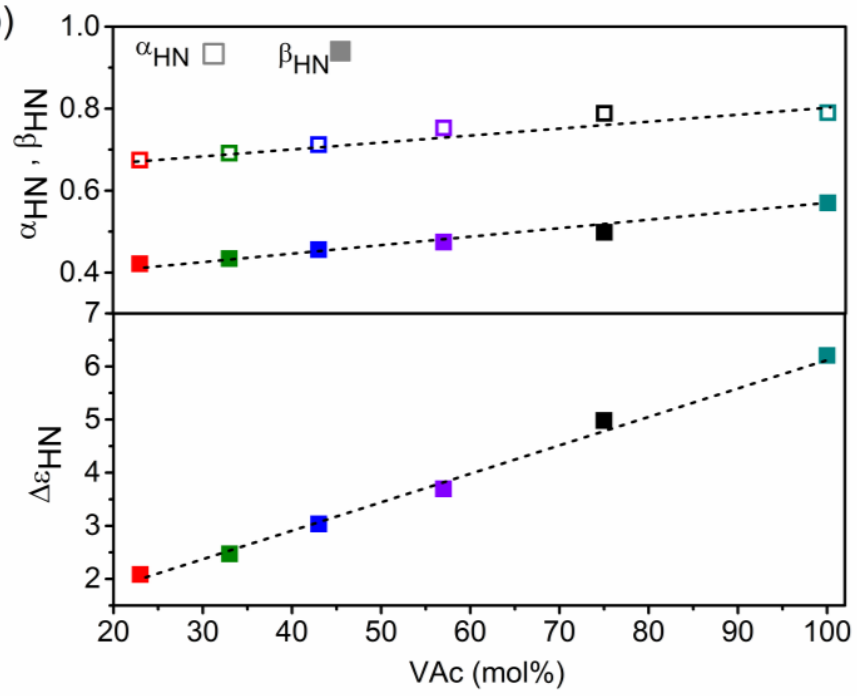

c)

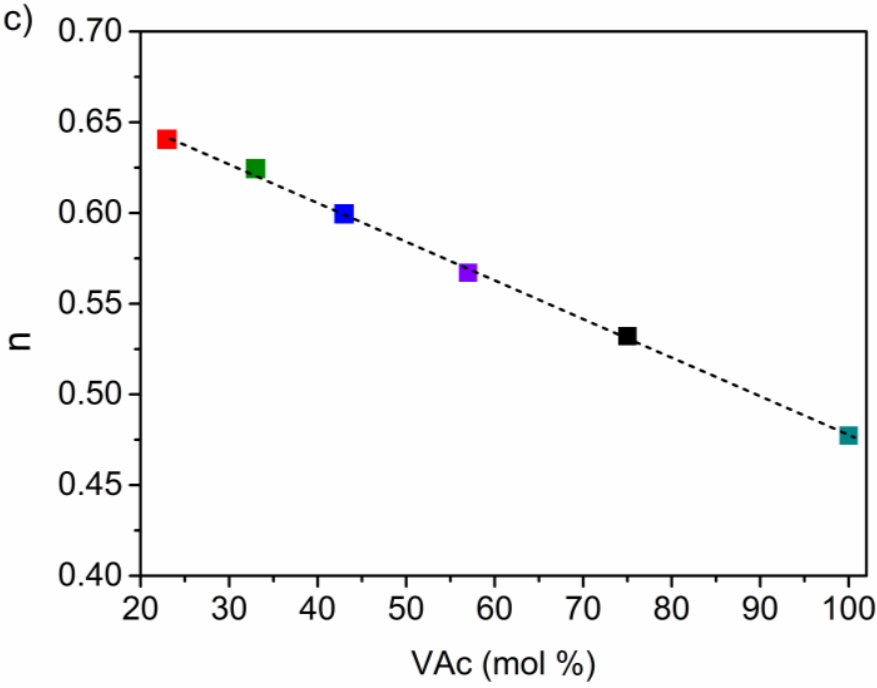

Figure 5: a) Master plot frequency for the higher and the lower VAc content samples, PVAc and EVA50, respectively; b) Variations of the dielectric relaxation strength $\left(\Delta \varepsilon_{H N}\right)\left(\right.$ at $\left.T_{\alpha}+10^{\circ} \mathrm{C}\right)$ and the broadening parameters
$\left(\alpha_{H N}\right.$ and $\left.\beta_{H N}\right)$ from the $\alpha$ relaxation; c) Coupling parameter $(n)$ calculated from the stretching parameter $\left(\beta_{K W W}\right)$ as a function of the VAc content.

As plotted in Fig. 5a, the peak becomes wider and more asymmetrical with the VAc content decreasing. The parameters that characterize the symmetric $\left(\alpha_{H N}\right)$ and the assymetric $\left(\beta_{H N}\right)$ broadening of the $\alpha$ relaxation are plotted in Fig. 5b. The values obtained for PVAc $\left(\alpha_{H N}=0.79\right.$ and $\left.\beta_{H N}=0.57\right)$ are similar to the shape parameters reported in the literature $\left(\alpha_{H N}=0.80\right.$ and $\beta_{H N}=0.50$ [42]). A slow and significant decrease of the values of the symmetrical and asymmetrical parameters was noted for the EVA copolymers when the VAc content decreases. As reported in the literature, the non-Debye relaxation behavior in the time domain $(t)$ is empirically described by the KohlrauschWilliams-Watts (KWW) function as follows [49]:

$\Phi(\tau)=e^{-\left(\frac{t}{\tau_{K W W}}\right)^{\beta} K W W}$

where $\Phi(\tau)$ is the correlation function, $\beta_{K W W}\left(0<\beta_{K W W} \leq 1\right)$ is the stretching parameter and $\tau_{K W W}$ is the relaxation time for $\beta_{K W W}=1$. The stretching parameter $\beta_{K W W}$ allows to compare an asymmetrical broadening behavior of the relaxation at short times (high frequencies) with the exponential decay (Debye relaxation with $\beta_{K W W}=1$ ). The $\mathrm{HN}$ parameters are correlated with $\beta_{K W W}$ as follows [50]:

$\log \frac{\tau_{H N}}{\tau_{K W W}} \approx 2.6\left(1-\beta_{K W W}\right)^{0.5} e^{\left(-3 \beta_{K W W}\right)}$

A good approximation of Eq. 9 is given by the following equation:

$\beta_{K W W} \approx\left(\alpha_{H N} \beta_{H N}\right)^{0.813}$

In our case, the $\beta_{K W W}$ value decreases from 0.52 for PVAc to 0.36 for EVA50. Such decrease can be explained by a higher heterogeneity of the relaxation time. According to Ngai et al. [51], the stretching parameter is correlated to the strengthening of the coupling $(n)$ as follows: $\beta_{K W W}=1-n$ (Fig. 5c). Then, the $\beta_{K W W}$ decrease (increasing $n$ value) with the VAc content decreasing can be associated with a broader relaxation time distribution of the $\alpha$ relaxation.

The dielectric relaxation strength $\left(\Delta \varepsilon_{H N}\right)$ is related to the dipolar density in the material. The dependence of $\Delta \varepsilon_{H N}$ with temperature $T$ was established by KirkwoodFröhlich as follows [52]:

$\Delta \varepsilon_{H N}=\frac{1}{3 \varepsilon_{0}} g \frac{\mu^{2}}{k_{B} T} \frac{N}{V}$

where $\varepsilon_{0}$ is the permittivity of the vacuum, $g$ is the Kirkwood-Fröhlich factor describing the static correlation between the dipoles, $\mu$ is the mean dipole moment of the process under consideration, and $N / V$ is the density of dipoles involved in the relaxation processes. In our case, the highest value of $\Delta \varepsilon_{H N}$ was obtained for PVAc $(\sim 6.2)$ and is in good agreement with values reported in the literature $(\sim$ $6.5[53])$. As to the EVA copolymers, the $\Delta \varepsilon_{H N}$ value decreases linearly with the VAc mol \% content decreasing (Fig. 5b), and this behavior is related to the decrease of the 
dipole density $(N / V)$ (Eq. 11). At a given temperature (in our case $T_{\alpha}+10^{\circ} \mathrm{C}$ ) and considering that for the VAc group only one dipole is presented in the backbone structure (i.e. the dipolar moment of the ethylene is negligible compared to the VAc one), the dielectric strength may be correlated to the VAc content (Fig. 5b). The decrease of $\Delta \varepsilon_{H N}$ can be related to a decrease of cooperativity [54] confirming the concomitant decrease of $\Delta \varepsilon_{H N}$ and $\xi_{\alpha}$ with the VAc content increase.

From the literature data, it is known that the cooperativity reduction in a system is generally caused by two mains parameters: chemical/physical modifications of the intermolecular interactions $[\mathbf{2 3}, \mathbf{3 9}]$ and/or confinement effects $[9,11]$. The confinement effect does not seem to be a possible cause for our set of samples, as the materials are fully amorphous (no crystalline phase, nor interface). The decrease of the VAc group amount seems to be directly correlated with the reduction of the intermolecular interactions. Several studies confirm the correlation between the strength of intermolecular interactions (Van der Waals) and the decrease of cooperativity $[\mathbf{7 , 9 , 5 5 ]}$.

It is known that the temperature dependence of the $\alpha$ relaxation process in polymers is well fitted by the VogelFulcher-Tammann (VFT) [56] equation when plotted against 1/T (Fig. 6):

$\tau=\tau_{0} \exp \left(\frac{D T_{0}}{T-T_{0}}\right)$

where $D$ is a dimensionless steepness parameter and $T_{0}$ is the reference Vogel temperature.

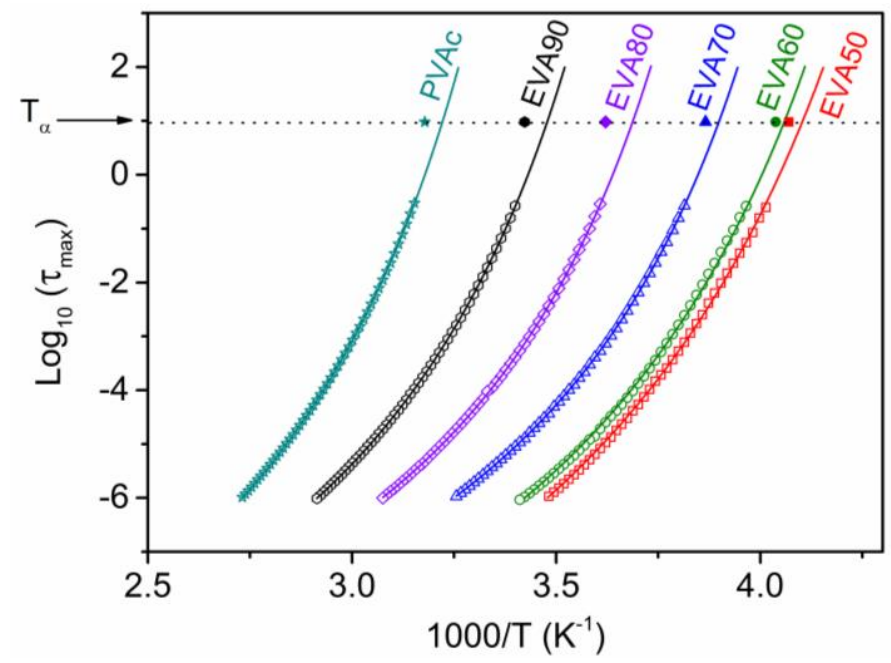

Figure 6. Temperature dependence of the $\alpha$ relaxation time for PVAc and EVA copolymers. $T_{\alpha}$ from MT-DSC measurements are reported in filled symbols.

The extrapolated $T_{g}$ values from BDS measurements are comparable to the values obtained from MT-DSC measurements $\left(T_{\alpha}\right)$ (Fig. 6). By normalizing the temperature scale with the extrapolated $T_{g}$ from BDS measurements, the Angell's plot is obtained (Fig. 7).

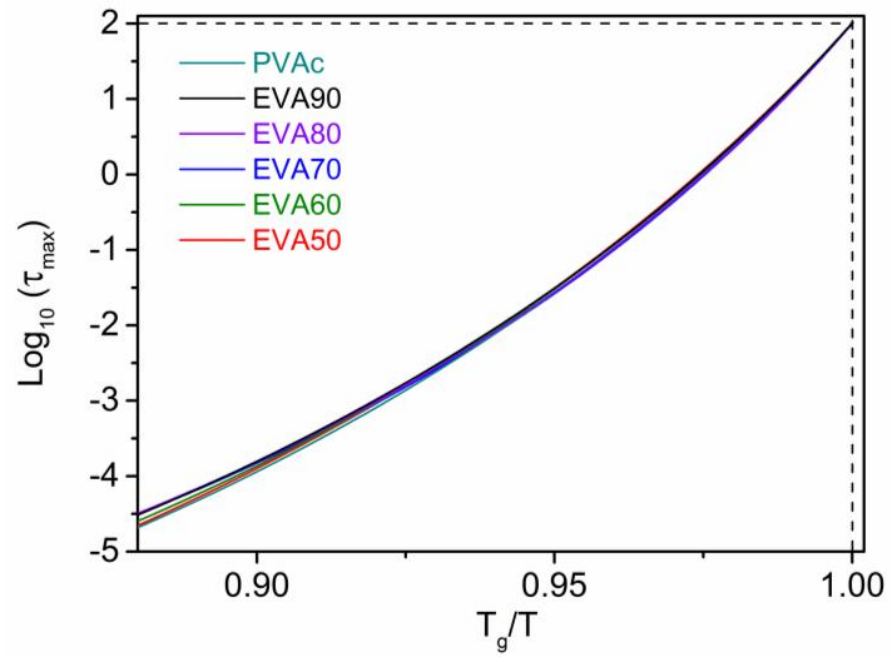

Figure 7. Angell's plot $\left(\log _{10}\left(\tau_{\max }\right)\right.$ versus $\left.T_{g} / T\right)$ for PVAc and EVA copolymers.

As observed from the Angell's plot, the temperature dependence of the relaxation time is similar for PVAc and EVA copolymer samples. The fragility index can be estimated from the VFT fit parameters (Eq. 1 and 12) for a reference relaxation time equal to $100 \mathrm{~s}[\mathbf{5 7 , 5 8}]$. The calculated fragility index $(m)$ (Eq. 1) shows a practically constant value for the studied EVA copolymers $(\sim 85-90)$. It can be observed from the Arrhenius plot (Fig. 6) that the structural relaxations for all the samples are quite similar with a slight shift in the $1 / T$ scale. This result is quite surprising because, as usually reported in the literature, a significant change in the glass transition temperature is associated with a modification in the steepness of the structural relaxation $[\mathbf{5 , 6}]$. Some authors even tried to quantify a correlation between $T_{g}$ and the fragility index [5]. In our case the main feature of studied EVA polymers is that the ethylene backbone remains unchanged with only a reduction of the dipole amount (VAc content). For PVAc, the dipoles are localized on the pending VAc group along the ethylene backbone. For EVA50, the dipole content, $i$. $e$. VAc group, is less than $25 \%$ compared to PVAc. The reference material is $\mathrm{PE}$, i.e. the polymer with only ethylene groups and no VAc dipole. It could be expected that extrapolating the fragility variations of the EVA copolymers would lead to a value close to the PE fragility index. In the literature the reported fragility index for PE is $\sim 45$ [15] $\left(m_{P E^{*}}\right.$ in Fig. 8). However, this value is estimated for a semicrystalline PE with a relaxation time equal to $1 \mathrm{~s}$. By using the relaxation map reported for PE [10] and by applying Eq. 12, the slope calculated at $100 \mathrm{~s}$ corresponds to a fragility close to $80\left(m_{e x t} P E\right.$ in Fig. 8). This value confirms well the fragility tendency for the amorphous and the nonconstrained phases in the EVA copolymers.

The dielectric relaxation behavior of semicrystalline materials with the VAc content $\leq 40$ wt. $\%$ was studied by Kummali et al. [27]. It was reported that the VAc segmental mobility is strongly affected by the high crystallinity of the samples. Furthermore, an extremely broad relaxation process is observed extending over more than four decades and two contributions were considered to explain the dielectric relaxation behavior (a constrained and 
a nonconstrained components). Actually, as reported in the literature for other polymers, a restriction of the motion of amorphous chain segments near crystalline phase causes an heterogeneous dispersion of the segmental $\alpha$ relaxation processes $[\mathbf{1 0 , 2 9 , 5 9 , 6 0 ]}$

It is possible to extract the fragility values for semicrystalline EVA from Kummali's works [27]. Indeed, BDS analysis of semicrystalline EVA shows that the microstructure must be described as crystalline PE phase, interfacial constrained EVA regions and nonconstrained amorphous regions with coexisting VAc and noncrystallized ethylene units. Using data for nonconstrained EVA amorphous phase, the $T_{\alpha}$ and fragility index values are plotted in Fig. 8. It can be noticed that even in the nonconstrained amorphous regions of EVA, the $m$ values remain constant whatever the VAc content. For the lowest (PE) and highest (PVAc) VAc contents, quite similar fragility values were obtained. In this context, the following hypothesis could be made: for ethylene backbone polymers, the steric hindrance and the polarity of the side group play an important role on the glass transition temperature but not on the fragility. This hypothesis will be checked in the near future for others polymers. So one can conclude that the relaxation time vs. temperature in the glass transition region has the same tendency. This important result is clearly supported by several studies which point out a strong correlation between fragility index and backbone stiffness [6].

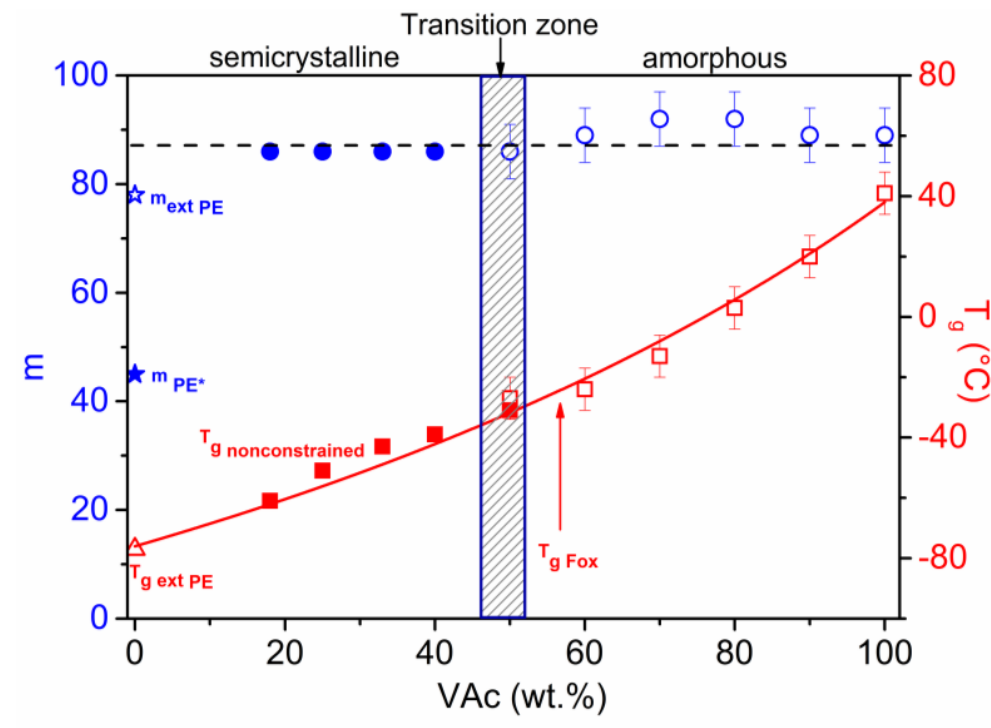

Figure 8 . The variation of fragility index $(m)$ and glass transition temperature $\left(T_{g}\right)$ with the VAc content. Values for EVA copolymers: empty symbols for the amorphous and transition domains and filled symbols for the semicrystalline domain [27]. The $T_{g}$ value calculated with the Fox law's is presented with a red continuous line.

Thus, the cooperativity/fragility relationship depends on the studied system. Several studies have reported the correlation or the anticorrelation between both parameters in complex systems (constrained amorphous phase, different backbone stiffness, dipole changing in the polymer chain or in a composite system) $[\mathbf{9 , 1 7 , 2 3 , 2 6 , 2 9 , 3 9 ] . ~}$ The interest of the present work comparing to the literature is to study simple systems, i.e. fully amorphous with a similar stiffness of the backbone. In the literature, the Kuhn length could be viewed in a first approximation as a measure of the polymer chain stiffness [61]. For the studied polymers, its value is almost constant with $13.6 \AA$ (PVAc) [61, 62] and $15.4 \AA$ (PE) [63]. These values support the idea of similar backbone stiffness for all the samples. In addition, only the quantity of the same dipolar group is varied. So, the constant value of fragility $(m \sim 85-90)$ and the decrease of cooperativity length scale (from 3.0 to $2.1 \mathrm{~nm}$ ) with the VAc content decreasing allow us to conclude that a cooperativity/fragility correlation is not always present.

The presence of ethylene groups can cause the polymer plasticization. So a decrease of the glass transition temperature is expected with the increasing of ethylene content, i.e decreasing VAc content, in the nonconstrained amorphous fraction (see in Fig. 8). On the other hand, as the reactivity ratio of ethylene and VAc is close to one, one can conclude that EVA is a random copolymer [64]. Therefore, the $T_{g}$ values for EVA copolymers can be estimated from the Fox's law. The glass transition temperature for PVAc determined in this work is in agreement with the values reported in the literature (from $30^{\circ} \mathrm{C}[65]$ to $40^{\circ} \mathrm{C}[\mathbf{5 , 2 3}]$ ). In the case of $\mathrm{PE}$, the determination of the glass transition remains complicated due to the high degree of crystallinity $\left(X_{c} \sim 50-90 \%\right.$ [66] $)$. Davis et al compared 50 studies performed for $T_{g}$ determination of $\mathrm{PE}$, and showed that the $T_{g}$ value may be either between $-133^{\circ} \mathrm{C}$ and $-111^{\circ} \mathrm{C}$ or between $-88^{\circ} \mathrm{C}$ and $-73^{\circ} \mathrm{C}$ depending on the sensitivity of the measurement method [67]. From the relaxation map of PE reported by Ngai et al [10], the $T_{g B D S} P E$ at $\tau=1 \mathrm{~s}$ is obtained at $-73^{\circ} \mathrm{C}$. By applying the Fox's law to our data (Fig. 8) the best fit (adjusted R-square $=0.98$ ) is obtained for a value of $T_{g P E}$ equal to $-77^{\circ} \mathrm{C}$. This value is obtained from nonconstrained fraction of EVA and, thus, should be seen as the $T_{g}$ value of a fully amorphous PE.

\section{Conclusions}

A constant value of the fragility for polymers with different VAc contents, from PVAc $(100 \%$ VAc) to a nonconstrained EVA copolymer (50 wt.\% VAc), was obtained from BDS measurements. Moreover, a decrease of the cooperativity length with the VAc content decreasing was observed. By comparing the evolutions of the fragility and the cooperativity length, no direct correlation between these two parameters is put in evidence. The correlation between fragility and backbone stiffness reported in the literature is in agreement with the invariances of the Kuhn length and fragility index values for the sample set studied here. These new results seem to confirm a qualitative understanding of the fragility and should be supported with other polymeric systems. Furthermore, the cooperative motions are governed by the intermolecular interactions. In this study, the decreasing size of the cooperative length in fully amorphous polymers, from PVAc to EVA50, is correlated to the decrease of the dipole amount, i.e. the VAc content. 


\section{$\underline{\text { Acknowledgements }}$}

The authors thank the HN Normandy Region, France and the University of Rouen for the financial supports for JASP and BR, respectively. Lanxess Co. society is acknowledged for the free giving of EVA pellets.

\section{$\underline{\text { References }}$}

1. Sokolov AP, Novikov VN, Ding Y. J PhysCondens Matter, 19 (2007), pp. 205116-1 - 205116-8

2. Hodge IM. Macromolecules, 16 (1983), pp. 898902

3. Böhmer R, Ngai KL, Angell CA, Plazek DJ. J Chem Phys, 99 (1993), pp. 4201-4209

4. Angell CA. In Relaxation in complex systems, Eds. Springfield Nat. Tech. Inf. Service, U.S. Depth. of Commerce; USA (1985); Vol. 1, pp. 3

5. Qin Q, McKenna GB. J Non-Cyst Solids, 352 (2006), pp. 2977-2985

6. Kunal K, Robertson CG, Pawlus S, Hahn SF, Sokolov AP. Macromolecules, 41 (2008), pp. 7232-7238

7. Nakanishi M, Nozaki R. Phys Rev E, 84 (2011), pp. 011503

8. Huang D, McKenna GB. J Chem Phys, 114 (2001), pp. $5621-5630$

9. Arabeche K, Delbreilh L, Saiter JM, Michler GH, Adhikari R, Baer E. Polymer, 55 (2014), pp. 1546-1551

10. Ngai KL, Roland CM. Macromolecules, 26 (1993), pp. 6824-6830

11. Crétois R, Delbreilh L, Dargent E, Follain N, Lebrun L, Saiter JM. Eur Polym J, 49 (2013), pp. 3434-3444 12. Saiter A, Bureau E, Cabot C, Saiter JM. J NonCryst Solids, 352 (2006), pp. 5067-5071

13. Robertson CG, Santangelo PG, Roland CM. J NonCryst Solids, 275 (2000), pp. 153-159

14. Capaccioli S, Ruocco G, Zamponi F. J Phys Chem B, 112, (2008), pp. 10652-8.

15. Roland CM, Santangelo PG, Ngai KL. J Chem Phys, 111 (1999), pp. 5593-5598

16. Berthier L, Biroli G, Bouchaud JP, Cipelletti L, El Masri D, L'Hote D, Ladieu F, Pierno M. Science, 310 (2005), pp. 1797-1800

17. Pazmiño Betancourt BA, Douglas JF, Starr FW. Soft Matter, 9 (2013), pp. 241-254

18. Adam G, Gibbs JH. J Chem Phys, 43 (1965), pp. $139-146$

19. Solunov CA. Eur Polym J, 35 (1999), pp. 15431556

20. Miller AA. J Chem Phys, 49 (1968), pp. 1393-1397

21. Miller AA. Macromolecules, 11 (1978), pp. 859-

862

22. Donth E. The glass transition relaxation dynamics in liquids and disordered materials, Springer; Germany (2001); pp. 227

23. Hempel E, Hempel G, Hensel A, Schick C, Donth E. J Phys Chem B, 104 (2000), pp. 2460-2466

24. Ellison CJ, Mundra MK, Torkelson JM. Macromolecules, 38 (2005), pp. 1767-1778

25. Zhang C, Guo Y, Priestley RD. Macro Letters, 3 (2014), pp. 501-505

26. Sharma M, Madras G, Bose S. Macromolecules,48 (2015), pp. 2740-2750
27. Kummali MM, Alegría A, Miccio LA, Colmenero J. Macromolecules, 46 (2013), pp. $7502-7512$

28. Arsac A, Carrot C, Guillet J. J Therm Anal, 61 (2000), pp. 681-685

29. Delpouve N, Delbreilh L, Stoclet G, Saiter A, Dargent E. Macromolecules, 47 (2014), pp. 5186-5197

30. Hamonic F, Saiter A, Dargent E. Mater Lett, 128 (2014), pp. 12-14

31. Yamaki SB, Prado EA, Atvars TDZ. Eur Polym J, 38 (2002), pp. 1811-1826

32. Barbosa RV, Neto RB, Mauler RS, Perez Gorga CJ, Schneider CG, Simanke AG. J Appl Polym Sci, 97 (2005), pp. 1371-1376

33. Rijal B, Delbreilh L, Saiter JM, Schönhals A, Saiter A. J Therm Anal, 121 (2015), pp. 381-388

34. Paka J, Wunderlich B. Thermochim Acta, 367/368 (2001), pp. 229-238

35. Weyer S, Hensel A, Schick C. Thermochim Acta, 304/305 (1997), pp. 267-275

36. Lacey AA, Price DM, Reading M. In Modulated Temperature Differential Scanning Calorimetry, Springer; Berlin (2006); Vol. 1, pp. 1

37. Havriliak S, Negami S. J Polym Sci Pol Sym, 14 (1966), pp. 99-117

38. Ngai KL, Roland CM. Polymer, 43 (2002), pp. $567-573$

39. Hong L, Novikov VN, Sokolov AP. J Non-Cyst Solids, 357 (2011), pp. 351-356

40. Gómez-Ribelles JL, Vidaurre Garayo A, Cowie JMG, Ferguson R, Harris S, McEwen IJ. Polymer, 40 (1998), pp. 183-192

41. Alegría A, Guerrica-Echevarría E, Goitiandía L, Tellería I, Colmenero J. Macromolecules, 28 (1995), pp. 1516-1527

42. Wagner H, Richert R. Polymer, 38 (1997), pp. 255-

261

43. Svodova R, Pustková P, Málek J. Polymer, 49 (2008), pp. 3176-3185

44. Nguyen HK, Prevosto D, Labardi M, Capaccioli S, Lucchesi M, Rolla P. Macromolecules, 44 (2011), pp. 65886593

45. Füllbrandt M, Purohit PJ, Schönhals A. Macromolecules, 46 (2013), pp. 4626-4632

46. Buerger DE, Boyd RH. Macromolecules, 22 (1989), pp. 2699-2705

47. Smith GD, Liu F, Devereaux RW, Boyd RH. Macromolecules, 25 (1992), pp. 703-708

48. Bistac S, Vallat MF, Schultz J. Prog Org Coat, 37 (1999), pp. 46-59

49. Williams G, Watts DC. T Faraday Soc, 68 (1970), pp. $80-85$

50. Alvarez F, Alegría A, Colmenero J. Phys Rev B, 44 (1991), pp. 7306-7312

51. Ngai KL, Plazek DJ. J Polym Sci B, 24 (1986), pp. 619-632

52. Kremer F, Schönhals A. In Broadband Dielectric Measurement Techniques in Broadband Dielectric Spectroscopy, Ed. Springer; Germany (2002); pp. 10

53. Urakawa O, Ujii T, Adachi K. J Non-Cyst Solids, 352 (2006), pp. 5042-5049 
54. Prevosto D, Lucchesi M, Bertoldo M, Passaglia E, Ciardelli F, Rolla P. J Non-Cyst Solids, 356 (2010), pp. 568573

55. Grigoras CV, Grigoras AG. J Therm Anal, 103 (2011), pp. 661-668

56. Tamman G, Hesse W, Anorg Z. Allgemeine Chemie, 156 (1926), pp. 245-257

57. Shinyashiki N, Shinohara M, Iwata $\mathrm{Y}$, Goto T, Oyama M, Suzuki S, Yamamoto W, Yagihara S, Inoue T, Oyaizu S, Yamamoto S, Ngai KL, Capaccioli S. J Phys Chem B, 112 (2008), pp. 15470-15477

58. Roland CM. Soft Matter, 4 (2008), pp. 2316-2322

59. MaCrum NG, Read BE, Williams G. In Anelastic and Dielectric Effects in Polymeric Solids; Dover Publication; USA (1991); pp. 1

60. Wetton RE, Allen G. Polymer, 7 (1966), pp. 331365
61. Fragiadakis D, Runt J. Macromolecules, 43 (2010), pp. $1028-1034$

62. Tiagy M, Arbe A, Alegria A, Colmenero J, Frick B. Macromolecules, 40 (2007) pp. 4568 - 4577

63. Fetters LJ, Lohse DJ, Colby RH. Chain dimensions and entanglements spacings. In Physical properties of polymers handbook, Ed. Springer, USA (2007), pp 447 454

64. Eagles DC, Rudin A. Plast Rub Proc Appl, 9 (1988), pp. 163-166

65. Gospodinova G, Zlatkov T, Terlemezyan L. Polymer, 39 (1998), pp. 2583-2588

66. Richards RB. J Appl Chem, 1 (1951), pp. 370-376

67. Davis GT, Eby RK. J Appl Phys, 44 (1973), pp. 4274-4281 